Research Article

\title{
Factors Influencing BIM Adoption for Construction Enterprises in China
}

\author{
Ruixue Zhang, ${ }^{1}$ Yuyan Tang, ${ }^{1}$ Liang Wang ${ }^{D},{ }^{2}$ and Zeyu Wang ${ }^{3}$ \\ ${ }^{1}$ School of Business Administration, Liaoning Technical University, Fuxin 125105, China \\ ${ }^{2}$ School of Maritime Economics and Management, Dalian Maritime University, Dalian 116026, China \\ ${ }^{3}$ School of Management, Guangzhou University, Guangzhou 510006, China \\ Correspondence should be addressed to Liang Wang; liangwang@dlmu.edu.cn
}

Received 3 August 2020; Revised 21 October 2020; Accepted 6 November 2020; Published 29 November 2020

Academic Editor: Jiansong Zhang

Copyright (c) 2020 Ruixue Zhang et al. This is an open access article distributed under the Creative Commons Attribution License, which permits unrestricted use, distribution, and reproduction in any medium, provided the original work is properly cited.

The construction industry is one of the important pillars of the Chinese national economy. BIM, as a new information technology tool, provides an intelligent digital representation of buildings to support diverse activities and brings about a wide range of benefits throughout the life cycle of projects. However, BIM has not been widely adopted in construction enterprises in China. It is necessary to make a comprehensive and systematic analysis of the influencing factors for BIM adoption. This paper sums up 13 influencing factors from four aspects, namely, technology, economy, institution, and environment aspect. The questionnaire survey and statistical analysis were used to collect and process data which is applied to determine the influencing factors. Based on relevant literature, a hypothesis model was established by the structural equation modeling method. SPSS software and AMOS software were used to test the model. Then, the key factors influencing BIM adoption are induced. The results show that the key factors that influence BIM adoption in China include personnel quality, investment in personnel training, BIM standardization, and the influence of senior managers in the organization. Combined with the above conclusion, this paper puts forward some suggestions for promoting BIM adoption and specific measures to realize the wide application of BIM technology in the Chinese construction industry.

\section{Introduction}

Building information modeling (BIM) is a set of information technology that integrates technology and information closely and is widely used by the architecture, engineering, and construction (AEC) industries. BIM has the advantages of high visualization, effective coordination, and robust simulation, which can effectively promote collaboration among participants in the construction projects. BIM plays a synergistic role in the whole life cycle of the project [1] and has a significant effect on the innovation and promotion of construction enterprises [2]. The use of BIM will bring enormous benefits, including improving production efficiency and product quality, achieving sustainability, and providing broader opportunities for burgeoning industries in the construction industry [3-6]. In most developed countries, as its normative BIM standards, sufficient talents, and corresponding legal norms, the advantages of BIM are particularly prominent [7].

Although the potential benefits of BIM are appealing, its adoption rate varies among different countries [8]. Previous research indicated that BIM adoption and usage is increasing in most developed countries [9]. Nevertheless, the extent of BIM adoption is stagnant in developing countries. For most developing countries, BIM has not been applied in the whole construction cycle of construction projects [10]. Especially, in China, although BIM has experienced the stages of concept introduction, theoretical research, preliminary application, rapid development, and deep application in the past ten years, it has not yet penetrated the whole process of the project construction cycle. BIM adoption in small- and medium-sized enterprises in China is just at an elementary stage [11] even though the government has taken actions to promote the use of BIM [12]. There is no substantial change 
in the traditional construction industry up to now [13]. The wide BIM adoption is still facing challenges in China.

Recent studies reporting the factors influencing BIM adoption have been proposed in the very recent literature. BIM has led to the breakthrough development of the AEC industry. BIM adoption is facing the development trend from integration, collaboration, and multilevel [13]. It is a tool and a process and assists in building performance while improving the effective management of construction projects. Many challenges and problems have aroused with the rapid development of the construction industry, for example, large and complex construction technology, enormous investment, the determination of construction period, and the relationship between multiagent stakeholders [14]. There are many obstacles in the practical implementation process as well such as the lack of relevant professional talents, difficulties in coordination between the main bodies, and poor software compatibility $[15,16]$. Several researchers found out that BIM adoption in enterprises is still low due to limited cooperation, dispersal stakeholder, and existing risk [17]. In the aspect of BIM adoption, it is concluded that whether to use BIM to complete a construction project is not only limited by the user's individual willingness but also depends on whether the senior managers within the organization want to use it for information management in the whole life cycle of the project [18].

Although existing literature on BIM adoption is very extensive, some deficiencies still exist. It is evident from the aforementioned previous studies that they analyzed the BIM adoption issue in a particular aspect. For instance, a model was proposed to predict project owner's BIM adoption behaviors in reference to the particular BIM practices in China [19]. Cao et al. discussed that the motivation of design units and general contractors in BIM adoption is closely related to the project scale and organizational nature [11]. Also, most studies are based on a specific adoption model perspective to study the influencing factors. Ahuja et al. developed a model using the technology-organization-environment framework to investigate factors influencing BIM adoption and reasons for the slow adoption [20]. Qin et al. proposed an integrated TAM (technology acceptance model) and TOE (technology-organization-environment) framework to investigate factors that hinder BIM adoption in the construction industry [21]. The TOE framework identifies technology, organization, and environment as three groups of contextual factors for organization to adopt innovations [22]. Besides, Songer et al. proposed to introduce economic factors into the adoption framework [23]. At present, from the perspective of the Chinese construction enterprises, the research on factors influencing BIM adoption is not deep enough. Furthermore, there is a lack of empirical research. It is therefore expedient to carry out an explicit study that comprises a comprehensive analysis of BIM adoption in all AEC firms in China. This study distinguishes and discusses the key factors influencing BIM adoption from the perspective of all construction enterprises in China. Based on the technology adoption framework, a theoretical model of factors influencing BIM adoption is constructed. The data are analyzed with statistical methods, and the influence degree is sorted and arranged. In addition, based on the research results of BIM adoption model, this paper analyzes and puts forward reasonable suggestions from the four dimensions of adoption strategy, investment planning, government departments, and the internal environment within the organization. It improves the scientific level of decision-making and promotes the BIM adoption in China's construction enterprises.

This paper aims to reveal factors influencing BIM adoption among construction enterprises in China. The study proposes a means for influencing factor analysis method by adopting structural equation modeling. Also, AMOS and SPSS software were used to analyze the data results. The following research questions will be answered in this paper:

(1) What is the current situation of BIM adoption and how to classify the factors influencing BIM adoption in construction enterprises?

(2) What are the key factors influencing BIM adoption and how do they affect adoption efficiency in construction enterprises in China?

(3) How to realize the rapid development of Chinese construction enterprises by improving BIM adoption efficiency?

The remainder of this paper is organized as follows: Section 2 reviews previous research on BIM adoption in construction enterprises. Section 3 elaborates the research methodology and proposes research hypotheses. Data collection and data processing are displayed in Section 4. Section 5 tests the hypothesis model from the perspective of exploratory factor and confirmatory factor. Section 6 discusses the critical influencing factors and corresponding strategies. Section 7 summaries this paper and explores future research on BIM adoption.

\section{Literature Review}

2.1. BIM Adoption Research. BIM has become increasingly popular in construction enterprises over the past few years. Many research studies have been performed worldwide to identify factors that influence the adoption of BIM $[8,24-26]$. Through the study of BIM adoption in Chinese construction enterprises, it is found that the key factors are attitude, technology, and organization [26]. At the organizational level, BIM adoption has gone through three stages: the first stage is the interdisciplinary object-based modeling process, the second is the synergy based on the established model, and the last is the network-based synergy [27]. This three-stage BIM adoption model has been used in the United States, Australia, and other developed countries. They are aiming to make BIM widely adopted [28, 29]. On the contrary, compared with developed countries, developing countries have not formed such a three-stage process to support BIM adoption. For example, the BIM adoption level is not very high in China [30, 31]. The maturity of BIM adoption is considered to be very low in India [25]. In the construction industry, designers are the first to use BIM to 
complete engineering projects [3]. In terms of BIM adoption, construction enterprises have been at the forefront. In general, the design team will give priority to BIM adoption in the course of the project [32]. Hence, BIM adoption is suitable and efficient for improving productivity effects in construction enterprises in order to promote the proceeds throughout the whole life cycle.

So as to determine the factors influencing BIM adoption, many theoretical models have been developed, such as technology acceptance model and technology-organizationenvironment framework. Previous studies have attempted to study technology adoption through innovation diffusion. Technology Adoption Model is one of the most commonly used framework models from individual and organizational perspectives. However, a few scholars point out that technology adoption model, Theory of Planned Behavior, and Unified Theory of Acceptance and Use of Technology are mostly used to study the adoption problem between individuals [33]. The technology-organization-environment framework model focuses on different stages of adoption and different levels of organizational adoption process.

Based on the theory of reasonable behavior, Davis studies the technology acceptance model. TAM is widely used to explain the information technology adoption or acceptance behavior. It consists of two specific factors that affect user behavior, namely, how and when to use new technologies: perceived usefulness and perceived ease of use [34]. These two parameters are based on the "Selfefficacy theory" research [35]. Although there are a number of empirical studies, people's intention to use determines whether a new technology can be well adopted. TAM is widely used to predict various types of technology acceptance behavior activities, for example, virtual reality [36], smart grid [37], and transportation [38]. However, it needs to be integrated into a broader model, including variables related to human and social factors [39]. Technology-organization-environment framework was first proposed by Tornatzky and Fleischer [40]. It represents a company's model of technological, organizational, and environmental impacts in the process of adopting and implementing technological innovation [41]. In the meantime, it describes three aspects in which an enterprise decides to adopt technology: technology, organization, and environment. Technical background refers to the internal and external technologies currently applied by the organization, as well as technologies that are already on the market but not yet used by the company. Organizational background refers to the size of the company, organizational structure, and human resources. Environmental background includes factors beyond organizational control, such as competition, partners, and industry environment. In addition to the above, Songer et al. proposed to introduce economic factors into the technology adoption framework considering that enterprises may try to use information technology at a lower cost [23]. Because it contains a new factor, environmental factor, the TOE framework structure is considered to be able to better explain the innovation diffusion within enterprises [33, 42].
2.2. Influencing Factors of BIM Adoption. At present, BIM is gradually spread all over the world, and the utilization rate of relevant software is also gradually increasing [43]. Compared with most developed countries, BIM adoption has just begun in developing countries. For instance, the development depth and breadth of BIM in China are far less than that in Europe. Therefore, there is still a lot of room for improvement in its application and promotion [44]. Through the research and analysis of the promotion factors of BIM adoption in the Chinese engineering design industry, it can be concluded that the factors influencing BIM adoption include software advantages, laws and regulations, localization degree, standards, BIM application cases, and experience [45]. Technology, legal system, personnel, organization, and economy are also the main factors influencing BIM adoption [46]. It is found that the support of senior managers within the organization, personal subjective will, and technical specifications affect whether designers want to adopt BIM [47]. Meanwhile, high-quality employees, efficient management and leadership, the availability of information, and the complexity of the project itself will also affect the smooth implementation of BIM [48, 49]. From the individual, technical and organizational levels, design units, and construction enterprises pay more attention to the factors influencing BIM cooperation [50].

According to the research on the factors influencing BIM adoption in the European construction industry, it is concluded that the obstacle factors include more time spent in training staff, high investment, and large amounts of labor [51]. In addition, in the practical application of BIM adoption, the lack of relevant laws and regulations, relevant standards and implementation guidelines, and unclear ownership will also hinder the implementation effect [52]. Based on the economic, technical, and legal perspectives, the reasons hindering the application can be summarized, including contract mode and business model [53]. Under the current market background, there are still many problems in the application and in-depth development of BIM, for example, no consensus on BIM adoption, no clear provisions in existing laws and regulations, and lack corresponding industry standards [52]. The research studies the application and future development trend of BIM throughout the whole life cycle of construction projects such as interests, risks, and trends and analyzes the problems and challenges that will be faced in the application process [15]. Through the questionnaire survey, the key factors influencing BIM adoption are identified, including BIM experience, leader support, organizational, technical training, and other 12 influencing factors [54].

Most of the scholars' results are to analyze one aspect of the factors, and the comprehensive research and analysis of each factor is missing. Based on the structural equation model, this paper focuses on the factors influencing BIM adoption in construction enterprises in China, selecting technology, economy, institution, and environment as four potential variables and corresponding thirteen observation variables, analyzing the influence of each factor on BIM adoption, arranging from large to small on the basis of the factor load, and giving policy suggestions to promote BIM adoption. 


\section{Research Methodology}

There are many factors influencing BIM adoption. It is difficult to classify the key influencing factors reasonably only through the existing literature research methods. Therefore, combined with the research of existing literature with expert consultation and interview, the influencing factors summarized are designed into a questionnaire, which is issued and recycled through the Internet. This paper selects technology, economic, institution, and environment factors as four external latent variables, corresponding to thirteen observation variables, respectively, and BIM adoption is as internal latent variables.

3.1. Hypothesis. BIM technical characteristics normally reflect the applicability, ease of use, compatibility, and interoperability of its applications. Compared with traditional methods, BIM has great superiority. Using BIM requires specialists with relevant industry experience and knowledge. At present, the lack of technical personnel is a prominent problem in China $[55,56]$. The development of BIM is still in elementary. BIM brings quantifiable benefits, which can significantly offset the relevant application costs. However, it is difficult to capture the cost and benefit in the process of BIM adoption. Also, BIM adoption has a lot of intangible benefits, which increase the difficulty in calculating the return on investment [47]. Thus, the paper proposes the following hypotheses:

(i) H1: technological factor has an impact on BIM adoption.

(ii) H1a: technical advantage positively affects BIM adoption.

(iii) H1b: production efficiency positively affects BIM adoption.

(iv) H1c: the quality of employees within an organization positively affects BIM adoption.

BIM is widely used as new information technology. Although it will bring huge profits to enterprises and improve production efficiency, the initial cost investment is not small. Young et al. affirmed that the capital required for the procurement of BIM software and hardware equipment was considerable [57]. BIM technologies available for sale are costly for purchase and installation [58]. Memon et al. asserted that the transition from the traditional way to the emerging of BIM has huge cost constraints [59]. Hence, enterprises are not willing to implement the process unless they can link it with the substantial reduction of long-term benefits and training costs of their respective companies. Similarly, identifying the benefits of return on investment can improve the BIM adoption rate [60]. Also, the cost of personnel training and the cost of employing consulting units and experts are the expenses of BIM adoption [61]. Accordingly, this study proposes the following hypotheses:

(i) H2: economic factor has an impact on BIM adoption. (ii) H2a: the investment in technology research and development positively affects BIM adoption.

(iii) H2b: the investment in the application of software positively affects BIM adoption.

(iv) $\mathrm{H} 2 \mathrm{c}$ : train-related talents positively affect BIM adoption.

The maturity and standardization of BIM have a significant impact on the company's cognition of new technology. BIM localization contains not only the localization of software running environment but also the adaptation of local project characteristics [62]. BIM standardization defines the project stages, the deliverable, and the objectives to be achieved. BIM adoption needs the integration of many kinds of software. Only the unified data exchange standard can make the data transfer effectively [63]. National policies have a significant impact on the development of BIM adoption in the construction industry in China [64]. In recent years, the Chinese government has also published relevant policies to encourage BIM adoption. Therefore, we propose the following hypotheses:

(i) H3: institutional factor has an impact on BIM adoption.

(ii) H3a: improving law and system positively affects BIM adoption.

(iii) H3b: government subsidies and incentive policies positively affect BIM adoption.

(iv) $\mathrm{H} 3 \mathrm{c}$ : improving BIM standards positively affect BIM adoption.

Organizational support plays an important role in stimulating employee potential, allocating resources, and improving job performance [65-67]. Adequate organizational support will have an incentive effect on employees. They feel that they are trusted by the organization. Therefore, they will focus more on their own work and strive to achieve organizational goals. On the contrary, if the necessary support is lost, the work quality of employees will be greatly reduced or even worse $[68,69]$. Lin declared that organizational high-level support could improve employees' perceived usefulness and perceived ease of use of BIM adoption [70]. Based on the above, we propose the following hypotheses:

(i) H4: environmental factor has an impact on BIM adoption.

(ii) H4a: intraorganizational mandatory use positively affects BIM adoption.

(iii) H4b: intraorganizational emphasis positively affects BIM adoption.

(iv) H4c: intraorganizational encouragement positively affects BIM adoption.

(v) H4d: intraorganizational talent structure distribution positively affects BIM adoption.

Based on the above review, a theoretical framework is designed, as shown in Figure 1. The unidirectional arrows of this model shown in Figure 1 start from the independent 
variables and end at the dependent variables, implying the independent variables affect the dependent variable.

3.2. Structural Equation Model. Traditional analysis methods, such as multiple regression, path analysis, and traditional factors analysis, can deal with variables with observed values. Although the dependent variables are allowed to include measurement errors, it is required to assume that the observation values of independent variables have no errors. In many practical problems, the relationship between multi-index variables is complex. Sometimes, it is not always possible to use a set of independent variables to explain a dependent variable. Although traditional factor analysis can deal with measurement errors, it does not involve how to compare or test different models [71]. In this paper, the latent variables, the factors influencing BIM adoption, cannot be measured directly, and the questionnaire survey presents the difference in quantity. Therefore, the structural equation model is used as the analysis method in this paper.

The structural equation model is a statistical technique that is based on the covariance matrix of variables to analyze the relationship between variables. SEM was formally defined by Pearl [72]. The specific implementation is divided into five steps: model setting, model identification, model estimation, model evaluation, and model modification. It is mainly used to deal with the relationship between multiple causes, results, and problems with latent variables. It can deal with multiple variables at the same time. It also can compare and evaluate different theoretical models. Firstly, the model sets observation variables for potential variables that cannot be measured directly. Then, the relationship between each observation variable is analyzed to reflect each latent variable and its structural relationship. The advantages of the structural equation model are that it can deal with multiple dependent variables. It allows both independent and dependent variables to contain measurement errors. It can also simultaneously estimate the factor structure and factor relationship. It can allow a more elastic measurement model. It can estimate the fitting degree of the whole model [73]. Based on this theory, a conceptual model can be drawn, as shown in Figure 2.

\section{Data Analysis}

4.1. Design of Questionnaire. For the purpose of ensuring the validity of this questionnaire, it is designed from multiple angles. Through reading the relevant literature and expert interviews, combined with the characteristics of construction enterprises and BIM, a questionnaire has been designed. After the questionnaire is withdrawn, it is necessary to integrate information processing. The design of this questionnaire for this study was structured and multiple-choice type. It was divided into three parts. The first part comprised the basic information of the respondents. It includes personal information (gender, age, working years, and education level), basic information of the enterprise (enterprise-scale and enterprise nature), and understanding of BIM. These questions ensure the validity of the

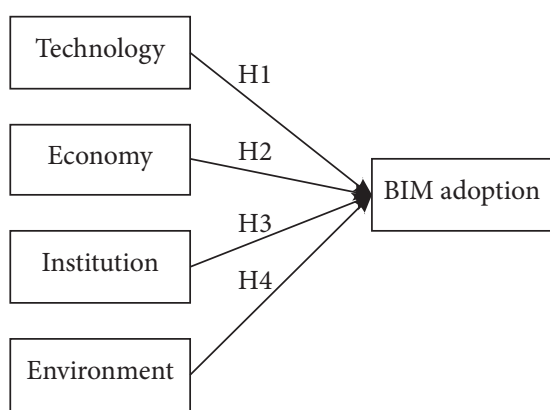

Figure 1: The theoretical model.

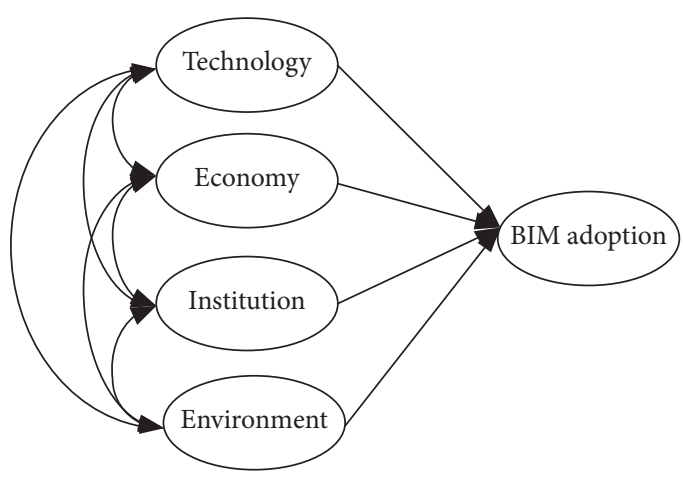

Figure 2: The conceptual model.

samples and allow the survey results to be classified and crossanalyzed. The second part is the variable measurement. It includes a research hypothesis based on the factors influencing BIM adoption in construction enterprises, which is tested in the form of scale. The third part is the special measurement items. This part of special measurement is mainly to collect some specific factors on the research status of BIM adoption and test the validity of this questionnaire. The aim of the part is to collect respondents' judgments on the degree of influence between variables. For example, the questions on the factors influencing BIM adoption among AEC firms in China were asked on a fivepoint Likert-type scale, with 1-5 indicating "strongly disagree," "disagree," "generally," "agree," and "strongly agree," respectively. All of these measurement items were adopted from existing studies and combined with practical situations relevant to BIM adoption in the Chinese construction industry.

4.1.1. Scale Development. In order to measure the reliability and validity of the factors influencing BIM adoption accurately in construction enterprises and ensure the rationality of the hypothetical model, the observation variable system scale of influencing factors is determined according to relevant literature and expert opinions, as shown in Table 1.

\subsection{Analysis of Basic Characteristics}

4.2.1. Statistical Analysis of Basic Information. The research objects of this survey are strictly limited to employees in construction industries, educators engaged in engineering 
TABLe 1: Measurement items.

\begin{tabular}{lcc}
\hline Number & Observation variable & Latent variable \\
A1 & Visibility advantage & Productivity and returns \\
A2 & Quality of employees in the organization & Technical factors \\
A3 & Technology adoption with a lot of money & Economic factors \\
B1 & Investment and application of technology & Institutional factors \\
B2 & Hire and train BIM-related talents & \\
B3 1 & Establish or improve laws and systems & Government subsidies or incentives \\
C2 & Improve standards to adapt localization & Environmental factors \\
C3 & BIM technology is mandatory & \\
D1 & Emphasis on technology adoption within the organization & \\
D3 & Encourage technology adoption within the organization & \\
D4 & Distribution of talent structure within the organization &
\end{tabular}

direction, and graduates with relevant internship experience. The method adopted is to send out the questionnaires online and fill in the questionnaires and collect it in a unified way finally. The questionnaire survey lasted as long as three months. A total of 100 questionnaires were distributed, and 85 valid questionnaires were finally selected under the premise of ensuring the quality of the questionnaire. The selected questionnaires data are used as the sample data for empirical analysis. In order to ensure the response rate of the questionnaire, anonymous survey was conducted to reduce the problem setting of personal information. In addition, one extra reward will be offered to the participants. This study screened the returned questionnaires from two perspectives to eliminate the invalid questionnaires: (1) the online electronic questionnaire takes less than one minute to answer. This part of the questionnaire is discarded because the research object did not answer it seriously; (2) if the respondents choose the answers to each index question with significant regularity, the questionnaire is considered to be invalid.

The proportion of men and women in this survey is about $3: 1$. The age of the respondents is mainly $35-45$-year-old. They have rich working experience to ensure the authenticity and accuracy of the data. Among them, 67\% have a bachelor's degree, $29 \%$ have a master's degree, and only $4 \%$ have a junior college degree or below. It indicates the higher education that respondents have, the better working environment, and working conditions they own. There are employees and interns of construction enterprises. Most of the working units are construction units. There are also a small number of design units, consulting units, and other units. There is a small part of education workers and experts in related fields who are engaged in engineering. For the working departments of the respondents, they are mainly concentrated in the engineering department. Also, the design department and cost department are in the minority. In terms of BIM proficiency, the majority of staff are familiar with BIM, and only $14.5 \%$ can skillfully use BIM. However, even $2 \%$ have not heard of BIM at all. The statistical analysis of basic information is shown in Table 2. It mainly focuses on the gender, age, educational background, working years, the nature of the enterprise, and the understanding of BIM of the selected sample population.
4.2.2. Descriptive Statistical Analysis of Sample Data. According to the third part of the questionnaire, four potential variables and thirteen corresponding observation variables that affect the BIM adoption in the construction enterprises in China are summarized. The mean value and standard deviation of each variable sample data shown in Table 3 are obtained through the descriptive analysis of the sample data under the selected variables by SPSS software.

The mean value represents the average size of the collected data, namely, the importance of the respondents to the BIM adoption efficiency of the Chinese construction enterprises affected by these factors. The standard deviation represents the dispersion or fluctuation of data points in a set of data sets. It can be concluded from the above that, for each potential variable, the mean and standard deviation of the observed variables are in a relatively stable value. Therefore, the data result is excellent; further research and analysis can be carried out.

\section{Model Hypothesis Test}

To ensure the model fitting degree and the validity of hypothesis test, SPSS software is used to test the reliability and validity of the collected data. In general, reliability and validity were the two most common indicators used to evaluate the measurement model. If the result is significant, then conduct the "violation estimation" test. If the residual estimation value is negative or the standardization coefficient is greater than 0.95 , it is illegal. After meeting the above requirements, the model fitness test is carried out to verify whether the hypothesis is tenable according to the results of the interpretation and analysis.

\subsection{Exploratory Factor Analysis}

5.1.1. Reliability Analysis. Reliability analysis, also known as the reliability test, is used to test whether the data collected by the questionnaire are consistent. The test method adopted is Cronbach's alpha coefficient. Generally, the coefficient is above 0.7. Previous studies suggested that Cronbach's $\alpha$ greater than 0.7 indicates acceptable reliability $[74,75]$. It 
TABLE 2: Basic information statistical analysis.

\begin{tabular}{|c|c|c|c|}
\hline Characteristic variables & Type & Frequency & Percentage (\%) \\
\hline \multirow{2}{*}{ Gender } & Man & 64 & 75.3 \\
\hline & Woman & 21 & 24.7 \\
\hline \multirow{3}{*}{ Age } & Under 25 years & 38 & 44 \\
\hline & 25-35 years & 36 & 43 \\
\hline & $35-45$ years & 11 & 13 \\
\hline \multirow{3}{*}{ Education level } & Junior college degree or below & 3 & 4 \\
\hline & Bachelor's degree & 57 & 67 \\
\hline & Master's degree and above & 25 & 29 \\
\hline \multirow{5}{*}{ Work unit } & Real estate units & 13 & 15.8 \\
\hline & Construction units & 39 & 45 \\
\hline & Design units & 12 & 14.6 \\
\hline & Advisory units & 11 & 13.4 \\
\hline & Others & 10 & 11.2 \\
\hline \multirow{4}{*}{ Work department } & Engineering department & 47 & 56.6 \\
\hline & Design department & 16 & 19.3 \\
\hline & Cost department & 9 & 10.8 \\
\hline & Others & 11 & 13.3 \\
\hline \multirow{4}{*}{ Familiarity with BIM } & Very familiar & 12 & 14.5 \\
\hline & Familiar & 49 & 59 \\
\hline & Not too clear & 20 & 24.1 \\
\hline & Never know & 2 & 2.4 \\
\hline
\end{tabular}

TABLE 3: Descriptive statistical analysis of sample data.

\begin{tabular}{|c|c|c|c|c|c|}
\hline Variable name & Number & Subject & Mean & Standard deviation & Variance \\
\hline \multirow{3}{*}{ Technical factors } & A1 & Visibility advantages & 3.05 & 0.936 & 0.876 \\
\hline & $\mathrm{A} 2$ & Productivity and return on investment & 2.81 & 0.876 & 0.767 \\
\hline & A3 & Quality of employees & 3.08 & 0.913 & 0.834 \\
\hline \multirow{3}{*}{ Economic factors } & B1 & Invest in technology adoption & 2.69 & 0.854 & 0.730 \\
\hline & $\mathrm{B} 2$ & Technology investment and applications & 2.76 & 0.805 & 0.649 \\
\hline & B3 & Hire and train BIM-related talents & 2.80 & 0.838 & 0.701 \\
\hline \multirow{3}{*}{ Institutional factors } & $\mathrm{C} 1$ & Prepare and improve laws and systems & 3.20 & 0.823 & 0.677 \\
\hline & $\mathrm{C} 2$ & Government subsidies or incentives & 3.07 & 0.793 & 0.629 \\
\hline & $\mathrm{C} 3$ & Improve standards to adapt localization & 3.20 & 0.793 & 0.628 \\
\hline \multirow{4}{*}{ Environmental factors } & D1 & Mandatory use of BIM & 2.72 & 1.051 & 1.105 \\
\hline & D2 & Emphasis on BIM adoption & 2.76 & 0.850 & 0.722 \\
\hline & D3 & Encourage BIM adoption & 2.69 & 0.869 & 0.754 \\
\hline & D4 & Distribution of talent structure & 2.76 & 0.850 & 0.722 \\
\hline
\end{tabular}

means that the data of the questionnaire have a good consistency.

According to SPSS, the reliability of the data collected in the questionnaire was tested and is shown in Table 4. The reliability of each dimension is greater than 0.7 , indicating that the reliability of each dimension meets the standard of this research, and the data reliability of each dimension is good.

5.1.2. Validity Analysis. The validity analysis represents the validity of the data. It judges the consistency between the hypothetical situation and the actual measured data. The higher the validity result value, the closer the relationship between the measurement results and the content to be investigated. Otherwise, the relationship is not close. Generally, the validity is usually divided into content validity and structure validity to analyze the validity of sample data.
TABLE 4: Reliability analysis.

\begin{tabular}{lcc}
\hline Level & $N$ & Cronbach's alpha \\
\hline Technology & 3 & 0.853 \\
Economy & 3 & 0.865 \\
Institution & 3 & 0.865 \\
Environment & 4 & 0.885 \\
\hline
\end{tabular}

Content validity refers to whether the selected topic can describe the variables reasonably and accurately. Structural validity refers to whether the selected topic is consistent with the purpose of this research. Structural validity is examined by discriminating validity and convergent validity [26]. Firstly, correlation analysis is conducted; KMO and Bartlett sphere tests are conducted. Bartlett sphere test and KMO sample measure are observed, as shown in Table 5. Only when the correlation is high, factor analysis can be carried 
TABLE 5: KMO and Bartlett sphere test.

\begin{tabular}{lcc}
\hline \multicolumn{2}{l}{ Kaiser-Meyer-Olkin measure of sampling adequacy } & 0.918 \\
\hline & Approx. chi-square & 838.267 \\
Bartlett's test of sphericity & $\mathrm{df}$ & 78 \\
& Sig. & 0.000 \\
\hline
\end{tabular}

out. The KMO value of this scale is 0.918 , which is greater than 0.8. It indicates that these data are very suitable for factor analysis. The significance probability of Bartlett's sphere test is 0.000 , less than 0.01 . It has passed the significance test with a significance level of $1 \%$. And it indicates that the data are relevant; that is, factor analysis can be carried out.

According to the software, the principal component information table can be obtained. If the eigenvalue is approximately greater than or equal to 1 , four factors will be approximately selected. And the cumulative contribution rate reaches $81.506 \%$. It shows that the four factors extracted from the 13 topics are ideal for the interpretation of the original data, as shown in Table 6.

According to the rotating component matrix, the factor attribution of each topic can be determined. The maximum variance method is used to rotate the factors to obtain the new factor load of each topic on each factor. The rotation component matrix is shown in Table 7.

5.2. Establishment of SEM. According to the data analysis above, it shows that the hypothetical conceptual model is basically reasonable. Technology, economy, institution, and environment can influence the BIM adoption in Chinese construction enterprises. Therefore, AMOS software is used to establish the structural equation model. And the hypothesis model and data are tested for confirmatory analysis and violation estimation. If there is a violation, the model needs to be modified and tested. If each estimation coefficient test is in a reasonable range, the model fitness test can be carried out. After testing and analysis, the estimated coefficients of each potential variable are positive and within a reasonable range. The structural equation model M1 of BIM adoption influencing factors is shown in Figure 3.

5.3. Confirmatory Factor Analysis. Based on the results of the exploratory factor analysis, a measurement model is established. Then, the model is verified by AMOS software. There are four latent variables and thirteen observational variables. Firstly, the structure validity is tested to get the whole fitting coefficient table. Chi-square degree of freedom index can avoid the influence of sample size on chi-square statistics. The reasonable index value is greater than 1 and less than 3. In this model, the absolute fitting index CMIN/ $\mathrm{DF}=1.656<3$, fitting ideal. The root mean square index of approximation error is less affected by the selected sample review, the reasonable index value is less than 0.08 , and the fitness degree of the standard model is acceptable. The absolute fitting index RMSEA $=0.089$, approximate to 0.08 , is acceptable. The goodness-of-fit index refers to the degree to measure whether the model fitness is good; when the index value is greater than 0.9 , it indicates the selected sample data and design. In this model, the absolute fitting index GFI $=0.857$ is close to 0.9 , acceptable. The relative fitting index $\mathrm{CFI}=0.953$; when it is greater than 0.9 , the result is good. The standard fitting index is to measure whether the set model and the selected data have a good matching degree; when the index value is greater than 0.9 , it means good matching. In this model, IFI $=0.954>0.9$, and the results fit well. TLI $=0.937$, greater than 0.9 , acceptable. $\mathrm{SRMR}=0.049$, less than 0.5 . Generally, the model fits well and has practical significance, as shown in Table 8 .

According to Table 8, the overall standardized test fitting degree of this model is ideal. Therefore, the composition reliability and average variance extraction test of latent variables are further constructed to judge that the model has a good internal quality. The calculation formula of component reliability and mean-variance extraction is as follows:

$$
\begin{aligned}
\mathrm{CR} & =\frac{\left(\sum \mu_{i}\right)^{2}}{\left(\sum \mu_{i}\right)^{2}+\sum \operatorname{Var}\left(\theta_{i}\right)}, \\
\mathrm{AVE} & =\frac{\sum \mu_{i}^{2}}{\sum \mu_{i}^{2}+\sum_{i} \operatorname{Var}\left(\theta_{i}\right)},
\end{aligned}
$$

where CR represents the composition reliability, AVE represents average variance extraction, $\mu i$ represents the standardized factor load of the observed variable, and $\theta i$ represents the standardized residuals of observed variables.

Through the data analysis by SPSS and AMOS, the parameter estimation table of the factor measurement model is obtained in Table 9. The nonstandard estimation parameters can judge that the scale is positive and significant. The standardized factor load of each topic is greater than 0.6. It indicates that each latent variable has high representativeness.

The SMC of each path is greater than 0.36. Most of them are above 0.5 , which means the topic has sufficient item reliability. The mean-variance (AVE) of each latent variable is greater than 0.5 , which indicates that the convergence validity is acceptable. And the combination reliability (CR) is greater than 0.8 , which indicates that there is sufficient internal consistency and the convergence validity is ideal.

Based on the data analysis above and Figure 3, the discriminant validity test is carried out. The correlation analysis of the four dimensions is conducted in turn. According to AMOS and Table 9, the discrimination validity analysis in Table 10 is summarized. There are significant correlations among technology, economy, institution, and environment $(P<0.01)$. The absolute value of the correlation coefficient is less than the square root of the corresponding AVE. It indicates that there is a certain correlation between the latent variables. And there is a certain degree of differentiation between them. Therefore, the discriminant validity of the scale data is ideal.

5.4. Model Interpretation and Analysis. The value between potential variables represents the degree of other variables changes caused by one variable. The data results show that 
Table 6: Principal component information.

\begin{tabular}{lccccc}
\hline \multirow{2}{*}{ Principal component number } & \multicolumn{3}{c}{ Original } & \multicolumn{2}{c}{ Rotating the sum of squares and loads } \\
& Total & \% of variance & Cumulation\% & Total & \%ariance \\
\hline 1 & 7.810 & 60.080 & 60.080 & 3.723 & 28.639 \\
2 & 1.311 & 10.087 & 70.167 & 2.807 & 21.595 \\
3 & 0.924 & 7.106 & 77.273 & 2.566 & 19.740 \\
4 & 0.550 & 4.233 & 81.506 & 1.499 & 11.533 \\
5 & 0.469 & 3.607 & 85.113 & & \\
6 & 0.401 & 3.086 & 88.200 & & \\
7 & 0.325 & 2.499 & 90.699 & & \\
8 & 0.255 & 1.963 & 92.661 & & \\
9 & 0.251 & 1.934 & 94.596 & & \\
10 & 0.209 & 1.611 & 96.207 & & \\
11 & 0.193 & 1.484 & 97.691 & & \\
12 & 0.170 & 1.304 & 98.995 & & \\
13 & 0.131 & 1.005 & 100.000 & & \\
\hline
\end{tabular}

TABLE 7: Rotating component matrix.

\begin{tabular}{lccccc}
\hline \multicolumn{5}{c}{ Items } & \multicolumn{5}{c}{ Factor loading values } & Factor \\
& 1 & 2 & 3 & 4 & \\
\hline A1 & 0.758 & & & & Technology \\
A2 & 0.850 & & & & \\
A3 & 0.841 & & & & Economy \\
B1 & & 0.821 & & & \\
B2 & & 0.855 & & & Institution \\
B3 & & 0.793 & & & \\
C1 & & & 0.815 & & \\
C2 & & & 0.833 & & \\
C3 & & & 0.833 & & 0.661 \\
D1 & & & & 0.880 & Environment \\
D2 & & & & 0.850 & \\
D3 & & & & 0.889 & \\
D4 & & & & & \\
\hline
\end{tabular}

path coefficients are all positive. Technical factors, economic factors, institutional factors, and environmental factors are the main factors influencing BIM adoption in construction enterprises in China. The hypothesis model is basically established. Through the analysis of potential variables and observation variables, the observation variables closely related to the potential variables can be obtained. According to the factor load, the main factors influencing BIM adoption in construction enterprises are further explained, as shown in Figures 4 and 5 .

As can be seen from the two figures, they represent standardized parameter estimation and nonstandardized parameter estimation in the hypothesis model used by AMOS. According to the above reliability and validity analysis and confirmatory factor analysis, the structural equation model of factors influencing BIM adoption is tested and revised. It is obvious that the key factors affecting the BIM adoption efficiency can be compared and analyzed by each data representing different meanings. From the correct model, it can be concluded that the key factors influencing BIM adoption in AEC firms in China contain technical factors, economic factors, institutional factors, and environmental factors.

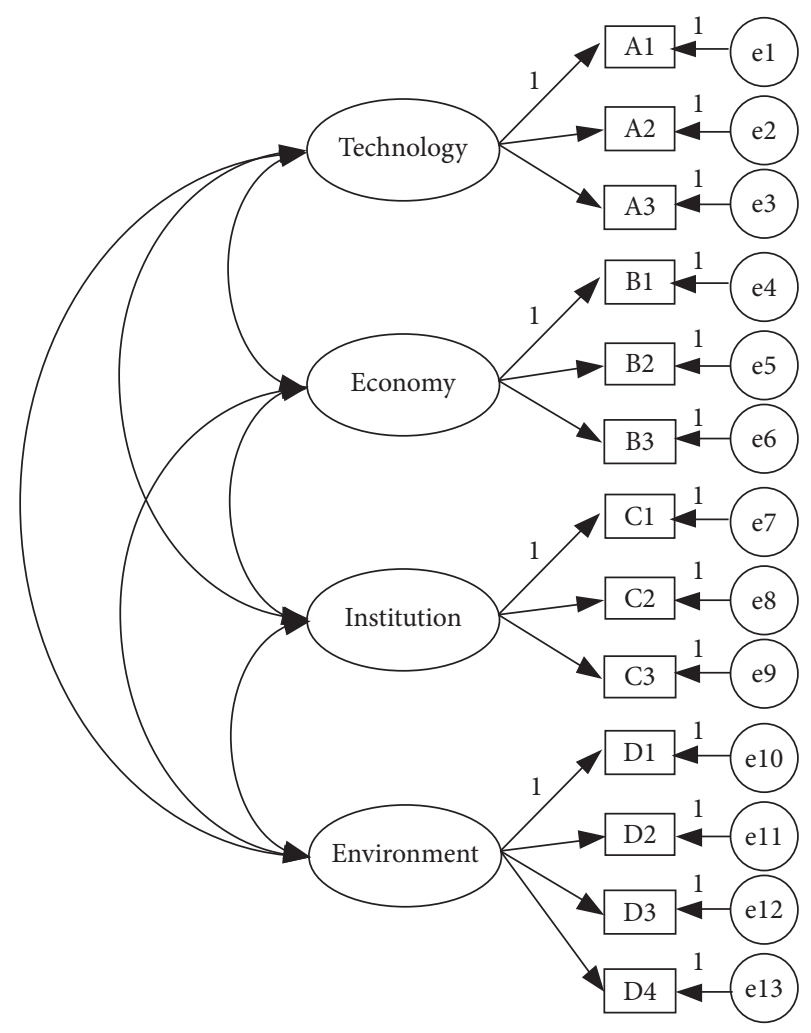

Figure 3: Structural equation model M1.

Technological factor has an impact on BIM adoption; namely, $\mathrm{H} 1$ is correct. Technical factors include staff quality, production efficiency, and visibility advantage. The factor load of employee quality is the largest. It shows that the BIM adoption in Chinese construction enterprises has a greater impact on the quality of internal personnel. And the high quality of employees is beneficial to improve the competitiveness of enterprises. Second is production efficiency, and the software of BIM plays a positive role in improving production efficiency and expanding the company's revenue. Compared with other software, BIM has good visibility. It is also one of the factors that affect the BIM adoption. 
TABLE 8: Overall fit index calculation.

\begin{tabular}{lccccccc}
\hline CMIN/DF & RMSEA & GFI & AGFI & CFI & IFI & TLI & SRMR \\
\hline 1.656 & 0.089 & 0.857 & 0.78 & 0.953 & 0.954 & 0.937 & 0.049 \\
\hline
\end{tabular}

TABLE 9: Factor measurement model parameter estimation.

\begin{tabular}{|c|c|c|c|c|c|c|c|c|c|c|}
\hline \multirow{2}{*}{ Title } & \multirow{2}{*}{ Path } & \multirow{2}{*}{ Factor } & \multicolumn{8}{|c|}{ Estimation of parameter significance } \\
\hline & & & Unstd. & S.E. & $T$-value & $P$ & Std. & SMC & CR & AVE \\
\hline A1 & $<<--$ & Technology & 1.000 & & & & 0.725 & 0.526 & 0.856 & 0.667 \\
\hline A2 & $<---$ & Technology & 1.107 & 0.160 & 6.923 & $* * *$ & 0.857 & 0.734 & & \\
\hline A3 & $<---$ & Technology & 1.157 & 0.167 & 6.925 & $* * *$ & 0.860 & 0.740 & & \\
\hline B1 & $<---$ & Economy & 1.000 & & & & 0.801 & 0.642 & 0.866 & 0.684 \\
\hline B2 & $<---$ & Economy & 0.956 & 0.126 & 7.569 & $* * *$ & 0.813 & 0.661 & & \\
\hline B3 & $<---$ & Economy & 1.059 & 0.136 & 7.786 & $* * *$ & 0.865 & 0.748 & & \\
\hline $\mathrm{C} 1$ & $<---$ & Institution & 1.000 & & & & 0.767 & 0.588 & 0.867 & 0.685 \\
\hline $\mathrm{C} 2$ & $<---$ & Institution & 1.063 & 0.142 & 7.497 & $* * *$ & 0.847 & 0.717 & & \\
\hline C3 & $<--$ & Institution & 1.086 & 0.144 & 7.544 & $* * *$ & 0.865 & 0.748 & & \\
\hline D1 & $<---$ & Environment & 1.000 & & & & 0.684 & 0.468 & 0.896 & 0.685 \\
\hline D2 & $<---$ & Environment & 1.048 & 0.147 & 7.117 & $* * *$ & 0.887 & 0.787 & & \\
\hline D3 & $<---$ & Environment & 1.025 & 0.149 & 6.884 & $* * *$ & 0.849 & 0.721 & & \\
\hline D4 & $<---$ & Environment & 1.034 & 0.147 & 7.050 & $* * *$ & 0.875 & 0.766 & & \\
\hline
\end{tabular}

${ }^{* *}$ The mean $P$ value is less than 0.001 .

TABle 10: Differential validity analysis.

\begin{tabular}{lcccc}
\hline & Technology & Economy & Institution & Environment \\
\hline Technology & 0.667 & & & \\
Economy & $0.452^{* *}$ & 0.684 & & \\
Institution & $0.439^{* *}$ & $0.315^{* *}$ & 0.685 & \\
Environment & $0.394^{* *}$ & $0.408^{* *}$ & $0.296^{* *}$ & 0.685 \\
Average & 0.817 & 0.827 & 0.828 & 0.828 \\
square root & & & & \\
\hline
\end{tabular}

** The mean $P$ value is less than 0.01 , and the diagonal is the extraction amount of variance of AVE evaluation.

Economic factor has an impact on BIM adoption; namely, $\mathrm{H} 2$ is correct. Economic factors include training professionals, software application, and investment in R\&D. The factor coefficient of training related talents is the largest. It indicates that most companies pay more attention to personnel training. They think that strengthening talent management will have an impact on BIM adoption. Secondly, the wide application level of software and large investment funds show that enterprises pay more attention to capital investment when adopting the technology. Some companies still dare not to take risks, so this is one of the factors that affect the BIM adoption.

Institutional factor has an impact on BIM adoption; namely, $\mathrm{H} 3$ is correct. Institutional factors include the completion of BIM standards, the introduction of relevant policies by the government, and the formulation of rules and regulations and laws. Improving BIM standards to adapt to localization and the government's incentive policies is similar. It shows that the government's corresponding behavior and its own standards will have a positive impact on BIM adoption. Therefore, the relevant government and organizations should introduce corresponding incentive policies to encourage users to actively adopt BIM.

Environmental factor has an impact on BIM adoption; namely, H4 is correct. Environmental factors include high-level personnel, making policies within the organization, and changing the organizational structure of personnel. High-level managers attach importance to the technology adoption and change in personnel organizational structure. It shows that, for the internal environment of the organization, the management opinion and management mode of top managers have a great positive impact on BIM adoption. Secondly, the company's internal incentive policies will also promote the application of technology by employees. For the sake of promoting BIM adoption in engineering projects, some rewards should be given to employees who use BIM to complete the project. We can also set up a BIM research group within the company to change the personnel organization structure to better promote the adoption and popularization of BIM.

Based on the above explanation, analysis and research suggestions can be concluded. The four main factors influencing BIM adoption in Chinese construction enterprises are not equally important, and there are also links and influences between them.

\section{Discussion and Recommendations}

6.1. Discussion. Combined with the above analysis results, the following conclusions can be proposed: the key factors influencing BIM adoption in Chinese construction enterprises include four main aspects, namely, the technical, economic, institutional, and environmental factors. Based on these results, the priority level of factors can be obtained to help the AEC firms in China in identifying the key factors for BIM adoption efficiency and developing and improving strategies effectively. This is helpful in putting forward the actions of capability improvement in combination with practice project, so as to enhance BIM adoption efficiency and accelerate the pace of information in the Chinese construction enterprises: 


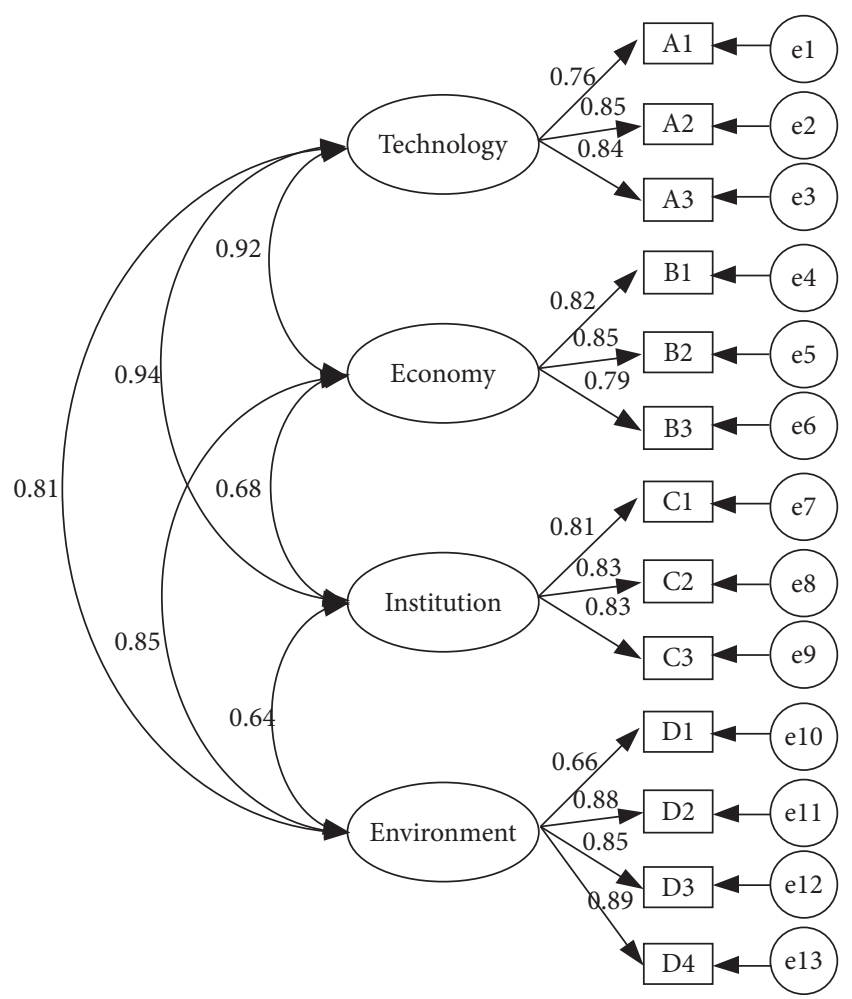

FIGURE 4: Standardized parameter estimation.

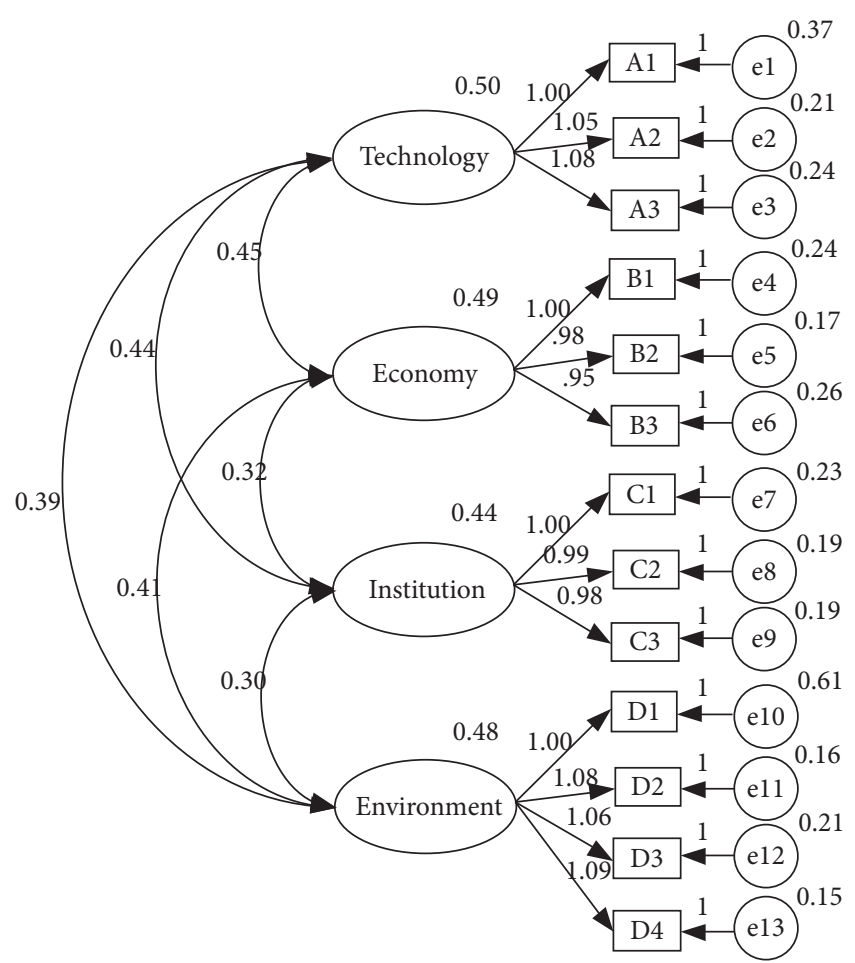

Figure 5: Nonstandardized parameter estimation.

(i) Factor 1: technology. On the basis of the factor loading, the influencing factors are ranked from high to low: production efficiency (A2), quality of employees (A3), and technical advantages (A1). High quality of staff is beneficial to enhance the competitiveness of enterprises. Thus, the awareness of technology adoption will be improved, which will have a positive impact on the BIM adoption. Therefore, construction enterprises pay attention to the cultivation and improvement of employees' skills with the organization. BIM, with its unique advantages, can promote technology adoption. Thereby, it can improve production efficiency and return. Hence, technical factors positively affect BIM adoption in China.

(ii) Factor 2: economy. According to the factor loading, the influencing factors are ranked from high to low: application of software (B2), investment in technology research and development (B1), and trainrelated talents (B3). To some degree, enterprises pay more attention to capital investment in BIM adoption. The more the investment, the higher the return, the greater the income. Economy is an important point in BIM adoption. However, most of small- and medium-sized Chinese construction enterprises dare not try to invest a lot of money to use BIM. They are afraid of risks in engineering projects, so they will not take action easily. The construction industry is still carried out in the traditional way. Therefore, economic factors are also the key factor affecting the BIM adoption efficiency.

(iii) Factor 3: institution. From the factor loading, the influencing factors are ranked from high to low: government subsidies (C2), improve standards to adapt localization (C3), and improve laws and systems (C1). The finding indicates that government policies also have an impact on BIM adoption. Especially, the external incentives from government will help enterprises' BIM adoption. Improving the corresponding rules and regulations shows that the improvement in laws will also promote the development of BIM. BIM standardization can provide guidance for BIM adoption and promote information delivery and sharing at all stages of the project. In addition, government departments can encourage policy actions to support enterprises to actively adopt BIM. It can also provide official and credible legal and regulatory guidance. More and more organizations would begin to use BIM. Therefore, institution factors will also affect BIM adoption efficiency.

(iv) Factor 4: environment. Based on the factor loading, the influencing factors are ranked from high to low: distribution of talent structure (D4), emphasis on technology adoption (D2), encourage technology adoption (D3), and mandatory use of BIM (D1). It mainly produces external motivation for construction enterprises in BIM adoption by means of compulsory or encouraging. Mandatory use of BIM may promote its implementation in the project and create a better external environment for its 
application. When BIM technicians and senior managers pay more attention to the use of BIM, it will positively promote BIM adoption. Thus, environment factors have an impact on BIM adoption.

\subsection{Recommendations}

6.2.1. Developing a Reasonable Adoption Strategy. The survey results show that the production efficiency of construction enterprises has a significant impact on BIM adoption. Compared with developed countries, the application depth of BIM is far from enough in China. Therefore, for the promotion and application of BIM, construction enterprises should formulate a clear and reasonable strategic plan to improve the BIM adoption efficiency. For example, employing high-quality employees and preferentially choosing projects requiring BIM is conducive to enhance the company's own competitiveness. It can improve production efficiency and expand industrial income and promote the process of BIM adoption faster and better. It is very important to draw up a reasonable strategic plan for BIM adoption. The performance of construction project will be improved based on the suitable applications associated with multiple BIM technologies. From the technical level, combined with the enterprise's own conditions, the reasonable technology adoption strategy is specified to improve the BIM adoption efficiency. BIM application platform of construction enterprises is the basis of BIM adoption. It is essential to establish a platform suitable for BIM adoption in construction enterprises. The platform can be established by the way of gradual expansion. Firstly, the BIM adoption, data, and other information on the project are integrated. Then, the professional application of BIM is realized. And the data association is completed.

6.2.2. Optimizing the Direction of Enterprise Investment. The economic factors that affect the BIM adoption in construction enterprises include the cost of software and hardware, personnel expenses, the cost of restructuring work mode, and the early benefits of using BIM. The survey results show that the cost of training BIM-related talents in technology investment has a significant impact on BIM adoption. A large amount of funds will be an indispensable key condition especially in the secondary development of BIM software and will be put into use. Because it has a certain degree of professionalism and involves many fields, enterprises will have a huge cost investment. The R\&D of software should be combined with the characteristics of the Chinese engineering management to speed up BIM's work efficiency. Therefore, the enterprise should make a reasonable resource allocation plan according to its actual situation, for instance, training or hiring BIM professionals in an all-round way, investing a lot of funds in BIM adoption, maximizing the value of BIM, and achieving a direct ratio between investment and return. For this reason, the more the investment, the higher the return, the greater the income. In this way, BIM should make a reasonable investment and investment in technology to the greatest extent.
6.2.3. Holistic BIM Standard. BIM was first originated in developed countries and then introduced into China. Most of the research results of BIM and other related contents are developed by external researchers. Therefore, sometimes, in the BIM adoption, due to its technical standards and legal environment that do not meet the relevant requirements of China's construction industry, the adoption efficiency will be reduced. The establishment of BIM standards is the core content of implementation. Only when the BIM adoption experience is refined into the standard of overall application of enterprises, can these experiences be truly transformed into productivity. Thus, the overall BIM adoption efficiency and quality can be improved. First, construction enterprises can refer to the regulations of local government or BIM technical standards formulated by developed countries, forming a set of holistic BIM standards for Chinese construction enterprises to better apply BIM. Second is formulating and improving BIM technical regulations and laws for the long-term development of construction enterprises, so as to adapt to the localization of BIM. Based on this, construction enterprises can protect their rights and interests by specifying their rights and interests in the contract and the delivery standard of the final model. In addition, relevant government departments support BIM adoption and introduce corresponding subsidy policies, which will also promote BIM adoption. Through the above, we can improve the BIM adoption efficiency from the institutional level.

\subsubsection{Changing the Internal Environment of Enterprises.} According to the survey results, top managers within the organization attach importance to the BIM adoption is a major influencing factor. If enterprises want to improve the BIM adoption efficiency, they should encourage senior leaders to accept BIM and enhance their trust in it. Therefore, we can formulate relevant policies and systems to improve the management's recognition of BIM. Construction enterprises can establish a good incentive mechanism to encourage the pilot work of various BIM projects, constantly accumulating experience in the pilot projects, training the team, and improving the BIM standard system. They can also appropriately change the internal talent structure allocation in order to make BIM better applied. For example, special funds are set up to encourage employees who study or apply BIM independently, establish a study group, add corresponding BIM assessment mechanism, hold some related competitions about BIM, and hold a seminar on BIM once a month. Above all, it can fully mobilize the enthusiasm of enterprise employees to adopt BIM and better promote the adoption efficiency of it.

\section{Conclusions}

Compared with developed countries, due to backward technology, lower economy, and incomplete BIM system, the effect of BIM adoption is pessimistic in construction enterprises in developing countries. Although BIM has been invented for years, the depth and breadth of its 
popularization are far from enough in developing countries, such as China. Also, there is a lack of comprehensive research on the impact of BIM adoption in Chinese construction enterprises. BIM adoption will encounter great challenges. Therefore, it is necessary to identify and discuss factors influencing BIM adoption in an all-round way. In this way, the key factors are determined. BIM adoption efficiency would be improved by taking appropriate strategies in Chinese construction enterprises.

This paper determines the influencing factors on the basis of previous literature, which is used to form a questionnaire. According to the collected data, the hypothesis model is established. For verifying and modifying the hypothesis model, the structural equation modeling method and AMOS and SPSS software are utilized. These factors were divided into four different levels in a hierarchy in accordance with SEM analysis. The results suggest that the influencing factors are arranged from large to small: technology $(\beta=0.50)$, economy $(\beta=0.49)$, environment $(\beta=0.48)$, and institution $(\beta=0.44)$. According to the factor load, in terms of technical factors, it shows that $\mathrm{A} 2(\beta=0.85)$ $>\mathrm{A} 3(\beta=0.84)>\mathrm{A} 1(\beta=0.76)$. In terms of economic factors, it shows that $\mathrm{B} 2(\beta=0.85)>\mathrm{B} 1(\beta=0.82)>\mathrm{B} 3(\beta=0.79)$. In terms of institutional factors, it shows that $\mathrm{C} 2(\beta=0.83)=\mathrm{C} 3$ $(\beta=0.83)>\mathrm{C} 1(\beta=0.81)$. In terms of environmental factors, it shows that D4 $(\beta=0.89)>\mathrm{D} 2 \quad(\beta=0.88)>\mathrm{D} 3 \quad(\beta=0.85)$ $>$ D1 $(\beta=0.66)$. Based on the weight, combined with the practical situation, BIM adoption strategies of construction industries are proposed. The theoretical contributions of this research are as follows: (1) key factors influencing BIM adoption from the perspective of all construction enterprises in China are distinguished and discussed; (2) the analysis system of BIM adoption influencing factors is established by the SEM method. The influencing factors are summarized and sorted from primary to secondary to determine the key factors. The findings of this study are expected to provide a better understanding of the essential elements affecting BIM adoption in the construction industries and guide industry practitioners in developing proper strategies to achieve more effective BIM adoption. Thus, for improving the efficiency faster, the construction enterprises with low efficiency in BIM adoption should focus on solving the main factors. On the contrary, various influencing factors could be balanced to define suitable policies and strategies for construction enterprises with relatively good BIM adoption efficiency. From the perspective of the world, China can be taken as an empirical case. For other developing countries, combined with their own characteristics, it more effectively improves the BIM adoption efficiency and improves the production efficiency of construction enterprises, furthermore developing the economy to a greater extent.

Besides, there are still some limitations on this study. This paper studies the key factors of BIM adoption from the perspective of all construction enterprises in China. When the questionnaire was issued to all types of Chinese construction enterprises, there was no classification study and discussion on different types of AEC firms in China. Owing to the influence of different factors on each type of construction enterprises is different, and the obtained results are also diverse. Therefore, based on large enough sample data and research literature, future research would provide a reasonable classification of Chinese construction enterprises. Then, the key influencing factors of BIM adoption will be studied for different types of construction enterprises from diverse perspectives.

\section{Data Availability}

The data used to support the findings of this study are available from the corresponding author upon request.

\section{Conflicts of Interest}

There are no conflicts of interest regarding the publication of this paper.

\section{Acknowledgments}

This research was funded by the National Natural Science Foundation of China (NSFC) (no. 71801119). The work described in this paper was also supported by the Social Science Planning Foundation of Liaoning Province (nos. L20BGL031 and L20BGL056), the Economic and Social Development Research Foundation of Liaoning Province (nos. 20211slqnkt-014 and 20211slqnkt-019) and the Fundamental Research Funds for the Central Universities (no. 3132020224).

\section{References}

[1] Y. Liu, S. van Nederveen, and M. Hertogh, "Understanding effects of BIM on collaborative design and construction: an empirical study in China," International Journal of Project Management, vol. 35, no. 4, pp. 686-698, 2017.

[2] M. Yalcinkaya and V. Singh, "Patterns and trends in building information modeling (BIM) research: a latent semantic analysis," Automation in Construction, vol. 59, pp. 68-80, 2015.

[3] McGraw Hill Construction, The Business Value of BIM for Owners, McGraw Hill, New York, NY, USA, 2014.

[4] Y. Arayici, P. Coates, L. Koskela et al., "Technology adoption in the BIM implementation for lean architectural practice," Automation in Construction, vol. 20, no. 2, pp. 189-195, 2011.

[5] D. Navendren, P. Manu, M. Shelbourn, and A. Mahamadu, "Challenges to building information modelling implementation in UK: designers' perspectives," in Proceedings of the 30th Annual ARCOM Conference, pp. 733-742, Association of Researchers in Construction Management, Portsmouth, UK, September 2014.

[6] R. Ramilo and M. R. B. Embi, "Critical analysis of key determinants and barriers to digital innovation adoption among architectural organizations," Frontiers of Architectural Research, vol. 3, no. 4, pp. 431-451, 2014.

[7] J. Feng, Research on Project Management Maturity Model Based on BIM Technology, Kunming University of Science and Technology, Kunming, China, 2014.

[8] N. Gu and K. London, "Understanding and facilitating BIM adoption in the AEC industry," Automation in Construction, vol. 19, no. 8, pp. 988-999, 2010.

[9] S. Ibrahim and I. Birshir, "Review of using building information modeling in Nigerian construction industry," Journal 
of Environmental Sciences and Policy Evaluation, vol. 2, no. 2, pp. 52-62, 2012.

[10] J. Park, H. Lee, and P. Kwak, "Case study on the application of BIM in Korea's civil engineering and improvement of interoperability of BIM models," International Journal of Software Engineering and Its Applications, vol. 9, no. 10, pp. 29-38, 2015.

[11] D. Cao, H. Li, G. Wang, and T. Huang, "Identifying and contextualising the motivations for BIM implementation in construction projects: an empirical study in China," International Journal of Project Management, vol. 35, no. 4, pp. 658-669, 2017.

[12] J. Zhang, Y. Long, S. Lv, and Y. Xiang, "BIM-enabled modular and industrialized construction in China," Procedia Engineering, vol. 145, pp. 1456-1461, 2016.

[13] MOHURD, China Construction Industry Information Development Report: BIM's Deep Application and Development, Ministry of Housing and Urban-Rural Development, Beijing, China, 2015.

[14] Y. Li, Z. Liao, and H. Yuan, "Investigating the Impacts of BIM on project parties and its application," Construction Technology, vol. 43, no. 6, pp. 522-523, 2014, in Chinese.

[15] S. Azhar, "Building information modeling (BIM): trends, benefits, risks, and challenges for the AEC industry," Leadership and Management in Engineering, vol. 11, no. 3, pp. 241-252, 2011.

[16] S. Zheng, H. Si, and L. Zhang, "The empirical research of BIM technology adoption intention based on UTAUT," Science and Technology Management Research, vol. 19, pp. 230-235, 2016, in Chinese.

[17] P. Goodridge, J. Haskel, and G. Wallis, UK Innovation Index: Productivity and Growth in UK Industries, Imperial College, London, UK, 2012

[18] S. Lee, J. Yu, and D. Jeong, "BIM acceptance model in construction organizations," Journal of Management in Engineering, vol. 31, no. 3, 2015.

[19] H. Yuan, Y. Yang, and X. Xue, "Promoting owners' BIM adoption behaviors to achieve sustainable project management," Sustainability, vol. 11, no. 14, p. 3905, 2019.

[20] R. Ahuja, M. Jain, A. Sawhney, and M. Arif, "Adoption of BIM by architectural firms in India: technology-organization-environment perspective," Architectural Engineering and Design Management, vol. 12, no. 4, pp. 311-330, 2016.

[21] X. Qin, Y. Shi, K. Lyu, and Y. Mo, "Using a Tam-toe model to explore factors of building information modelling (Bim) adoption in the construction industry," Journal of Civil Engineering and Management, vol. 26, no. 3, pp. 259-277, 2020.

[22] C. Carnaghan and K. Klassen, "“Exploring the determinants of web-based E- business evolution in Canada," in americas conference on information systems (AMCIS)," p. 225, 2007.

[23] A. Songer, R. Young, and K. Davis, "Social architecture for sustainable IT implementation in AEC/EPC," in Proceedings of IT in Construction of Africa, Mpumalunga, South Africa, 2001.

[24] H. C. J. Linderoth, "Understanding adoption and use of BIM as the creation of actor networks," Automation in Construction, vol. 19, no. 1, pp. 66-72, 2010.

[25] A. Sawhney, State of BIM Adoption and Outlook in India, RICS School of Built Environment, Amity University, Noida, India, 2014.

[26] H. Xu, J. Feng, and S. Li, "Users-orientated evaluation of building information model in the Chinese construction industry," Automation in Construction, vol. 39, pp. 32-46, 2014.
[27] B. Succar, "Building information modelling maturity matrix," Concepts and Technologies, pp. 65-103, IGI Global, Hershey, PA, USA, 2010.

[28] A. Chew and M. Riley, "What is going on with BIM? On the way to 6D," International Construction of Law Review, vol. 30, pp. 253-265, 2013.

[29] NATSPEC, National BIM Guide v1.0, NATSPEC, Sydney, Australia, 2011.

[30] Y. X. Gong, "Analysis on the application status and development obstacles of BIM in China," Electronic Commerce, vol. 46, pp. 204-205, 2012.

[31] NBS International BIM Report, Newcastle upon Tyne, NBS International BIM Report, London, UK, 2016.

[32] A. Elmualim and J. Gilder, "BIM: innovation in design management, influence and challenges of implementation," Architectural Engineering and Design Management, vol. 10, no. 3-4, pp. 183-199, 2014.

[33] T. Oliveira and M. F. Martins, "Literature review of information technology adoption models at firm level," The Electronic Journal Information Systems Evaluation, vol. 14, no. 1, pp. 110-121, 2011.

[34] F. D. Davis, R. P. Bagozzi, and P. R. Warshaw, "User acceptance of computer technology: a comparison of two theoretical models," Management Science, vol. 35, no. 8, pp. 982-1003, 1989.

[35] A. Bandura and D. Cervone, "Differential engagement of selfreactive influences in cognitive motivation," Organizational Behavior and Human Decision Processes, vol. 38, no. 1, pp. 92-113, 1986.

[36] K. T. Manis and D. Choi, "The virtual reality hardware acceptance model (VR-ham): extending and individuating the technology acceptance model (TAM) for virtual reality hardware," Journal of Business Research, vol. 100, pp. 503-513, 2019.

[37] T. M. Broman, G. Schuitema, and J. Thogersen, "Responsible technology acceptance: model development and application to consumer acceptance of smart grid technology," Applied Energy, vol. 134, pp. 392-400, 2014.

[38] G. Prati, V. Marín Puchades, M. De Angelis et al., "Evaluation of user behavior and acceptance of an on-bike system," Transportation Research Part F: Traffic Psychology and Behaviour, vol. 58, pp. 145-155, 2018.

[39] P. Legris, J. Ingham, and P. Collerette, "Why do people use information technology? A critical review of the technology acceptance model," Information \& Management, vol. 40, no. 3, pp. 191-204, 2003.

[40] L. G. Tornatzky and M. Fleischer, The Processes of Technological Innovation, Lexington Books, Lanham, MD, USA, 1990.

[41] R. Drazin, "The processes of technological innovation," The Journal of Technology Transfer, vol. 16, no. 1, pp. 45-46, 1991.

[42] P.-F. Hsu, K. L. Kraemer, and D. Dunkle, "Determinants of E-business use in U.S. Firms," International Journal of Electronic Commerce, vol. 10, no. 4, pp. 9-45, 2006.

[43] J. X. Zhang, "Research on application obstacles of building information model in engineering design industry in China," Journal of Engineering Management, vol. 4, pp. 387-392, 2010.

[44] Q. H. He, L. L. Qian, Y. F. Duan, and Y. K. Li, "Application status and obstacles of BIM at home and abroad," Journal of Engineering Management, vol. 26, no. 1, pp. 12-16, 2012.

[45] Y. Li, Research on Influencing Factors of BIM Application in Construction Enterprises, Wuhan Technology University, Wuhan, China, 2015, in Chinese. 
[46] L. Y. Zhang, Y. W. Li, and Y. Gao, “Application obstacles and countermeasures of BIM technology," Journal of Civil Engineering and Management, vol. 3, pp. 65-154, 2013.

[47] D. Cao, G. Wang, H. Li, M. Skitmore, T. Huang, and W. Zhang, "Practices and effectiveness of building information modelling in construction projects in China," Automation in Construction, vol. 49, pp. 113-122, 2015.

[48] B. Ozorhon and U. Karahan, "Critical Success factors of building information modeling implementation," Journal of Management Engineering, vol. 33, no. 3, 2017.

[49] J. Won, G. Lee, C. Dossick, and J. Messner, "Where to focus for successful adoption of building information modeling within organization," Journal of Construction Engineering and Management, vol. 139, no. 11, 2013.

[50] Y. Liu, S. V. Nederveen, and M. Hertogh, "Understanding effects of BIM on collaborative design and construction: an empirical study in China," International Journal of Project Management, vol. 35, no. 4, pp. 686-698, 2016.

[51] Y. Han and P. Damian, "Benefits and barriers of building information modeling," in Proceedings of the 12th. International Conference on Computing in Civil and Building Engineering, Beijing, China, October 2008.

[52] A. Salman, H. Michael, and S. Blake, "Building information modeling (BIM): benefits risks and challenges," in Proceedings of the 44th ASC Annual Conference on CDROM, Auburn, Alabama, April 2008.

[53] U. Lsikdag, "Design patterns for BIM-based service-oriented architectures," Automation in Construction, vol. 25, pp. 59-71, 2012.

[54] A. Mutai, Factors Influencing the Use of Building Information Modeling (BIM) within Leading Construction Firms in the United States of America, Indiana State University, Terre Haute, IN, USA, 2009.

[55] Shanghai Construction Industry Association and Shanghai Luban Consulting Company, Annual Research Report on BIM Technology Application Status in Construction Enterprises, Shanghai Construction Industry Association and Shanghai Luban Consulting Company, Shanghai, China, 2014.

[56] X. Qin, M. Mancini, and A. Travaglini, "A comparative study on barriers between China and Italy in BIM adoption from the construction market perspective," Chinese Journal of Management, vol. 13, no. 11, pp. 1718-1721, 2016.

[57] N. W. Young, S. A. Jones, and H. M. Bernstein, Building Information Modeling Transforming Design and Construction to Achieve Greater Industry Productivity, McGraw-Hill Construction, New York, NY, USA, 2008.

[58] M. E. Obiegbu and F. O. Ezeokoli, "Building information modeling, a panacea for timely project delivery," in Proceedings of the River State Quantity Surveyor's Week Holding at the Arena Event Centre, Port Harcourt, Nigeria, 2014.

[59] A. H. Memon, I. A. Rahman, I. Memon, and N. A. Azman, "BIM in Malaysian construction industry: status, advantages, barriers and strategies to enhance the implementation level," Research Journal of Applied Sciences, Engineering and Technology, vol. 8, no. 5, pp. 606-614, 2014.

[60] R. Balocco, R. Mogre, and G. Toletti, "Mobile internet and SMEs: a focus on the adoption," Industrial Management \& Data Systems, vol. 109, no. 2, pp. 245-261, 2009.

[61] J. Li, Hinder Research of BIM Technology Diffusion, Harbin Institute of Technology, Harbin, China, 2014, in Chinese.

[62] Y. Li, BIM Application in the Building Construction Enterprise, Wuhan University of Science and Technology, Wuhan, China, 2015, in Chinese.
[63] M. R. Hosseini, E. Azari, L. Tivendale, and N. Chileshe, "Barriers to adoption of building information modeling (BIM) in Iran: preliminary results," in Proceedings of the 6th International Conference on Engineering, Project, \& Production Management (EPPM2015), Griffith University, Logan City, Australia, 2015.

[64] Y. Wang, BIM Technology Adoption Model and Implication Research, Harbin Institute of Technology, Harbin, China, 2013, in Chinese.

[65] R. Eisenberger, P. Fasolo, and V. Davis-LaMastro, "Perceived organizational support and employee diligence, commitment, and innovation," Journal of Applied Psychology, vol. 75, no. 1, pp. 51-59, 1990.

[66] L. M. Shore and S. J. Wayne, "Commitment and employee behavior: comparison of affective commitment and continuance commitment with perceived organizational support," Journal of Applied Psychology, vol. 78, no. 5, pp. 774-780, 1993.

[67] C. L. Pearce and P. A. Herbik, "Citizenship behavior at the team level of analysis: the effects of team leadership, team commitment, perceived team support, and team size," The Journal of Social Psychology, vol. 144, no. 3, pp. 293-310, 2004.

[68] R. Eisenberger, R. Huntington, S. Hutchison, and D. Sowa, "Perceived organizational support," Journal of Applied Psychology, vol. 71, no. 3, pp. 500-507, 1986.

[69] R. Mcmillan, Customer Satisfaction and Organizational Support for Service Providers, University of Florida, Gainesville, FL, USA, 1997.

[70] H.-F. Lin, "An investigation into the effects of is quality and top management support on ERP system usage," Total Quality Management \& Business Excellence, vol. 21, no. 3, pp. 335$349,2010$.

[71] S.-Y. Lee and X.-Y. Song, "Model comparison of nonlinear structural equation models with fixed covariates," Psychometrika, vol. 68, no. 1, pp. 27-47, 2003.

[72] J. Pearl, Causality: Models, Reasoning, and Inference, Cambridge University Press, Cambridge, UK, 2000.

[73] R. P. Bagozzi and Y. Yi, "On the evaluation of structural equation models," Journal of the Academy of Marketing Science, vol. 16, no. 1, pp. 74-94, 1988.

[74] J. C. Nunnally, Psychometric Theory, McGraw-Hill, New York, NY, USA, 2nd edition, 1978.

[75] J. F. Hair, R. E. Anderson, R. L. Atham, and W. C. Black, Multivariate Data Analysis with Readings, Prentice-Hall, Upper Saddle River, NJ, USA, 1998. 